\title{
WORKSHOP PENGEMBANGAN MEDIA PEMBELAJARAN BERBASIS INFORMATION AND COMMUNICATION TECHNOLOGY (ICT)
}

\author{
Ipah Muzdalipah', Ratna Rustina ${ }^{2}$, R. Reza El Akbar ${ }^{3}$ \\ 1,2,3 Universitas Siliwangi \\ ${ }^{1}$ ipahmuzdalipah@unsil.ac.id
}

\begin{abstract}
The purpose of this devotion enhances the insight and skills of teachers in SMK AS-SHOFA in developing ICT-based learning media. Facts on the field show that the skills of teachers in utilizing technological applications still not satisfactory enough. Many teachers find it difficult to use ICT as a learning medium. The implementation method of this devotion activity follows the activity of implementation of action research consisting of preparations, implementation (action), and reflection and evaluation. The results gained from this devotion are the increasing insight and awareness of teachers at SMK As-Shofa on the importance of using ICT in learning especially in implementing Kurtilas, increasing the skills of teachers in SMK As-Shofa in using ICT in learning Media, Guru is able to make learning media based ICT and use it in learning.
\end{abstract}

Keywords: workshop, learning media, ICT

\begin{abstract}
Abstrak
Tujuan dari pengabdian ini meningkatkan wawasan dan keterampilan guru-guru di SMK ASSHOFA dalam mengembangkan media pembelajaran berbasis ICT. Fakta di lapangan menunjukkan bahwa keterampilan guru dalam memanfaatkan aplikasi teknologi masih belum cukup memuaskan. Banyak guru yang merasa kesulitan menggunakan ICT sebagai media pembelajaran. Metode pelaksanaan kegiatan pengabdian ini mengikuti aktivitas pelaksanaan penelitian tindakan yang terdiri dari Persiapan, Pelaksanaan (tindakan), dan refleksi dan evaluasi. Hasil yang diperoleh dari pengabdian ini adalah Meningkatnya wawasan dan kesadaran guru-guru di SMK As-Shofa tentang pentingnya penggunaan ICT dalam pembelajaran terutama dalam mengimplementasikan Kurtilas, Meningkatnya keterampilan guru-guru di SMK As-Shofa dalam menggunakan ICT dalam media pembelajaran, Guru mampu membuat media pembelajaran berbasis ICT dan menggunakannya dalam pembelajaran.
\end{abstract}

Kata Kunci: workshop, media pembelajaran, ICT

\begin{tabular}{l|l|l} 
Submitted: 2020-07-09 & Revised: 2020-07-17 & Accepted: 2020-07-18
\end{tabular}

\section{Pendahuluan}

Pesatnya perkembangan teknologi informasi dewasa ini telah mengubah paradigma masyarakat dalam mencari dan mendapatkan informasi, tidak lagi terbatas melalui surat kabar, televisi, maupun radio, tetapi juga sumber-sumber informasi lainnya yang salah satunya melalui jaringan internet. Bidang pendidikan merupakan salah satu bidang yang mendapatkan dampak yang sangat besar dari perkembangan teknologi ini. Menurut Sahid (2016) dalam menyikapi perkembangan dan kemajuan Information and Communication Technology (ICT) tersebut, guru dituntut untuk menguasai teknologi (ICT) agar dapat mengembangkan materi-materi pembelajaran berbasis ICT dan memanfaatkan ICT sebagai media pembelajaran. Tujuannya adalah untuk memberikan kemudahan dan kesempatan yang lebih luas kepada pebelajar dalam belajar. Menurut Yamasari (2010) media adalah segala sesuatu alat komunikasi, baik cetak maupun audio visual, yang 
digunakan untuk menyampaikan informasi dari pengirim ke penerima pesan dan merangsang siswa untuk belajar. Dalam beberapa tahun terakhir, pemanfaatan ICT sebagai media pembelajaran dalam dunia pendidikan sudah mulai memasyarakat, mulai dari jenjang pendidikan dasar, menengah, sampai ke perguruan tinggi, meskipun variasi dan fokus pemanfaatannya berbeda-beda pada masing-masing institusi

Teknologi baru terutama dalam bidang ICT memiliki peran yang semakin penting dalam pembelajaran. Banyak orang percaya bahwa multimedia akan dapat membawa kita kepada situasi belajar dimana "learning with effort" akan dapat digantikan dengan "learning with fun". Penggunaan media berbasis ICT memberikan beberapa keuntungan, antara lain: (1) memvisualisasikan konsep-konsep abstrak, (2) mempermudah memahami materi-materi yang sulit, (3) Mensimulasikan proses yang sulit dilakukan secara manual, (4) menampilkan materi pembelajaran dalam berbagai format (multimedia) sehingga menjadi lebih baik menarik, dan terbaru (up to date) dari berbagai sumber,(5) memungkinkan terjadinya interaksi antara pebelajar dan materi pembelajaran, (6) mengakomodir perbedaan kecepatan dan gaya belajar siswa, (7) mengatasi keterbatasan ruang, waktu, dan tenaga,(8) mendukung perubahan peran guru kea rah yang positif sebagai fasilitator dan mediator dari posisi semula sebagai satu-satunya sumber pengetahuan, (9) meningkatkan keterampilan individu penggunanya. Dari beberapa keuntungan media berbasis ICT di atas, maka guru didorong untuk dapat mengembangkan media pembelajaran berbasis ICT dan diharapkan terampil dalam menggunakan teknologi informasi dan komunikasi sebagai media pembelajaran.

Menurut Ibrahim (dalam Santyasa, 2017) profesionalisme guru tidak hanya mencakup kemampuan membelajarkan siswa, tetapi juga kemampuan mengelola informasi dan lingkungan (yang meliputi tempat belajar, metode, media, sistem penilaian, serta sarana dan prasarana) untuk memfasilitasi kegiatan belajar siswa sehingga menjadi lebih mudah. Oleh karena perkembangan ilmu pengetahuan dan teknologi, khususnya ICT, telah memperkaya sumber dan media pembelajaran dalam berbagai bentuk seperti buku teks, modul, transparansi OHP, slide Power Point, gambar/foto, animasi, film/video, siaran televisi, siaran radio, hiperteks, halaman Web, program pembelajaran berbantuan komputer, dan software aplikasi pendukung pembelajaran, maka guru yang profesional harus mampu memilih, mengembangkan dan memanfaatkan berbagai jenis media pembelajaran dengan memanfaatkan kecanggihan ICT tersebut. Hal ini sesuai dengan pendapat Zainiyati (2017) yang menyatakan bahwa media berfungsi bukan hanya untuk mempermudah guru menyampaikan materi pelajaran akan tetapi juga untuk mempermudah siswa menangkap apa yang disampaikan guru.

Perkembangan kurikulum perlu ditunjang oleh kemampuan guru dalam mengembangkan media pembelajaran yang efektif untuk mencapai tujuan pembelajaran dan meningkatkan kualitas capaian pembelajaran yang diharapkan, karena menurut Muhson (2010) bahwa secara umum manfaat media dalam proses pembelajaran adalah memperlancar interaksi antara guru dan siswa sehingga kegiatan pembelajaran akan lebih efektif dan efisien. Perkembangan cara belajar melalui pengembangan kurikulum ke arah "student center learning" atau pembelajaran yang berpusat pada siswa serta pemanfaatan teknologi informasi dan komunikasi dalam proses pembelajaran yang sesuai dengan kurikulum 2013, mendorong para pendidik untuk mengembangkan kreativitas dalam mempersiapkan bahan atau materi ajar yang menarik dan terkini agar siswa dapat 
memahami konsep yang diajarkan. Dengan adanya peranan ICT dalam pembelajaran, pemanfaatan media memegang peranan penting dalam proses pemebelajaran. Dalam hal ini guru dituntut untuk dapat mengintegrasikan ICT dalam pembelajaran dengan pemanfaatan media yang lebih atraktif ssehingga pembelajaran dapat berlangsung interaktif, inspiratif, menyenangkan, menantang, efisien serta memotivasi peserta didik untuk berpartisipasi aktif, serta memeberikan ruang yang cukup bagi peserta didik untuk berkreasi dan mandiri sesuai dengan minat, bakat dan perkembangan psikologi peserta didik.

SMK AS-SHOFA merupakan sekolah swasta yang terletak di Kecamatan Padakembang Kabupaten Tasikmalaya, pada saat ini sekolah tersebut memiliki 30 orang guru yang mengampu mata pelajaran. Secara umum pembelajaran di SMK AS-SHOFA dilakukan melalui pertemuan tatap muka dan guru yang mengampu mata pelajaran menjadi satusatunya sumber informasi dari mata pelajaran yang bersangkutan. Walaupun demikian sebagai lembaga pendidikan SMK AS-SHOFA memiliki beberapa unit Komputer yang masih terbatas fungsinya untuk mata pelajaran TIK, sehingga masih dirasakan perlu pengoptimalan perangkat tersebut sebagai media pembelajaran tidak hanya untuk mata pelajaran TIK saja. Fakta di lapangan menunjukkan bahwa keterampilan guru dalam memanfaatkan aplikasi teknologi masih belum cukup memuaskan. Banyak guru yang merasa kesulitan dalam memanfaatkan ICT sebagai media pembelajaran karena tidak menguasai teknik penggunaan ICT dalam pembelajaran. Walaupun demikian, guru-guru belum begitu serius dalam menerapkan pemahaman pentingnya aplikasi teknologi pembelajaran seiring dengan perkembangan siswa yang semakin akrab dengan teknologi. Sentuhan teknologi yang masih sangat kurang membuat guru dan sekolah kurang kreatif dalam merancang kegiatan pembelajaran atau proses belajar mengajar yang masih tradisional sehingga berdampak pada rendahnya kemampuan analisis dan kemampuan komunikasi siswa.

Memperhatikan kondisi sekolah dengan keberadaan laboratorium yang memadai namun program pelatihan penggunaan ICT dalam pembelajaran pada guru-gurunya masih sangat kurang maka Kepala Sekolah di SMK AS-SHOFA dan Pelaksana IbBM memandang perlu untuk melaksanakan kegiatan pengabdian IbBM dengan melibatkan guru yang ada.

\section{Metode}

Kegiatan pengabdian ini dilaksanakan di SMK As-Shofa yang bertempat di Kecamatan Padakembang Kabupaten Tasikmalaya, dengan jumlah peserta sebanyak 20 orang guru perwakilan dari setiap mata pelajaran di sekolah tersebut. Pelaksanaan kegiatan pengabdian ini mengikuti aktivitas pelaksanaan penelitian tindakan yang terdiri dari Persiapan, Pelaksanaan (tindakan), dan refleksi dan evaluasi. Rincian metode pelaksanaan dijelaskan sebagai berikut:

a. Perencanaan

Kegiatan perencanaan sebagai berikut:

1. Melakukan koordinasi dengan LPPM-PMP Universitas Siliwangi dan SMK ASSHOFA; 
2. Sosialisasi Kegiatan Pengabdian kepada sekolah mitra dengan mengundang Dinas terkait, Kepala sekolah dan seluruh guru mitra;

3. Penyusunan program pengabdian berdasarkan hasil analisis situasi, analisis siswa, analisis materi dan analisis media.

4. Penyusunan diktat panduan penggunaan media pembelajaran berbasis ICT.

b. Pelaksanaan Tindakan

Pelaksanaan tindakan atau kegiatan ini pengabdian dilakukan dengan tahapan berikut:

1. Penyuluhan

Sebelum memberikan pelatihan atau keterampilan kepada guru-guru matematika di SMK AS-SHOFA, Tim Pengabdian Masyarakat akan memberikan penyuluhan terlebih dahulu tentang pentingnya penggunaan ICT sebagai media pembelajaran. Hal ini dimaksudkan agar guru-guru tidak sekedar memiliki keterampilan melainkan juga memiliki wawasan dan kesadaran pentingnya aplikasi teknologi dalam pembelajaran. Kegiatan penyuluhan ini berisi materi dan diseminasi hasil-hasil penelitian yang berkaitan dengan alat peraga.

2. Pengenalan

Setelah diberikan bekal umum terkait pentingnya penggunaan ICT sebagai media dalam pembelajaran, maka Tim Pengabdian Masyarakat akan memperkenalkan terlebih dahulu media pembelajaran yang atraktif dan interaktif.

Kegiatan pelatihan dilakukan setelah guru-guru memahami semua teknologi yang dapat digunakan untuk menyimpan, mengolah, menampilkan, dan menyampaikan informasi dalam proses komunikasi pembelajaran. Kegiatan ini dipandu oleh tim dan dibantu oleh diktat yang telah disusun oleh tim. Setelah itu, guru diminta membuat proyek mandiri yang akan dia tampilkan dalam pembelajaran.

3. Pendampingan

Kegiatan pendampingan dilakukan dengan cara memberikan bimbingan langsung kepada peserta yang belum paham penggunaan ICT dalam merancang dan membuat media pembelajan.

c. Refleksi

Refleksi dilakukan bersama antara tim, peserta dan mitra. Hal ini dilakukan untuk mengetahui seluruh proses pelaksanaan kegiatan. Mitra, peserta dan tim secara bersama melakukan refleksi untuk memberikan saran dan masukkan dari kegiatan pengabdian yang dilakukan.

d. Evaluasi

Kegiatan observasi dilakukan secara langsung oleh tim pelaksana. Observasi berupa hasil kerja peserta (guru mitra) terhadap pemanfaatan ICT sebagai media pembelajaran. Proses evaluasi dilaksanakan untuk mengetahui kekurangan dan kendala dalam pelaksanaan kegiatan pengabdian dan membahasa proyeksi pengabdian berikutnya berdasarkan refleksi dari pengabdian yang telah dilakukan. 


\section{Hasil dan Pembahasan}

Perkembangan Information and Communication Technology (ICT) atau Teknologi Informasi dan Komunikasi (TIK) dalam beberapa dekade terakhir berjalan sangat cepat sejalan dengan perkembangan teknologi telekomunikasi, termasuk jaringan komputer. Berbagai teknologi dan aplikasi pendukung juga telah dikembangkan sebagai upaya untuk mendukung dan mempermudah aktivitas kehidupan manusia dan organisasi, termasuk kegiatan belajar mengajar dalam dunia pendidikan. Dalam menyikapi perkembangan dan kemajuan ICT tersebut, guru dituntut untuk menguasai teknologi (ICT) agar dapat mengembangkan materi-materi pembelajaran berbasis ICT dan memanfaatkan ICT sebagai media pembelajaran. Tujuannya adalah untuk memberikan kemudahan dan kesempatan yang lebih luas kepada pebelajar dalam belajar.

Dalam beberapa tahun terakhir, pemanfaatan ICT dalam dunia pendidikan sudah mulai memasyarakat, mulai dari jenjang pendidikan dasar, menengah, sampai ke perguruan tinggi, meskipun variasi dan fokus pemanfaatannya berbeda-beda pada masing-masing institusi. Beberapa sekolah sudah melengkapi diri dengan fasilitas ICT guna mendukung proses belajar mengajar. Kehadiran dan kemajuan ICT di era komunikasi global dewasa ini telah memberikan peluang dan perluasan interaksi antara guru dan siswa, antar siswa, dan sumber-sumber belajar dapat terjadi kapan saja dan di mana saja tanpa dibatasi oleh ruang dan waktu. Selain itu, dengan bantuan ICT proses penyampaian dan penyajian materi pembelajaran maupun gagasan dapat menjadi lebih menarik dan menyenangkan. Disisi lain, kehadiran ICT sebagai teknologi baru memberikan tantangan kepada guru untuk mampu menguasainya sehingga dapat memilih dan memanfaatkan ICT secara efektif dan efisien di dalam proses belajar mengajar yang dikelolanya.

Kegiatan pelatihan dan lokakarya maupun workshop ICT bagi guru yang mengintegrasikan ICT di dalam kurikulumnya dapat meningkatkan keterampilan ICT dan keinginan mereka untuk mengintegrasikannya di dalam proses belajar mengajar. Oleh karena itu workshop pengembangan media pembelajaran berbasis ICT sangat diperlukan.

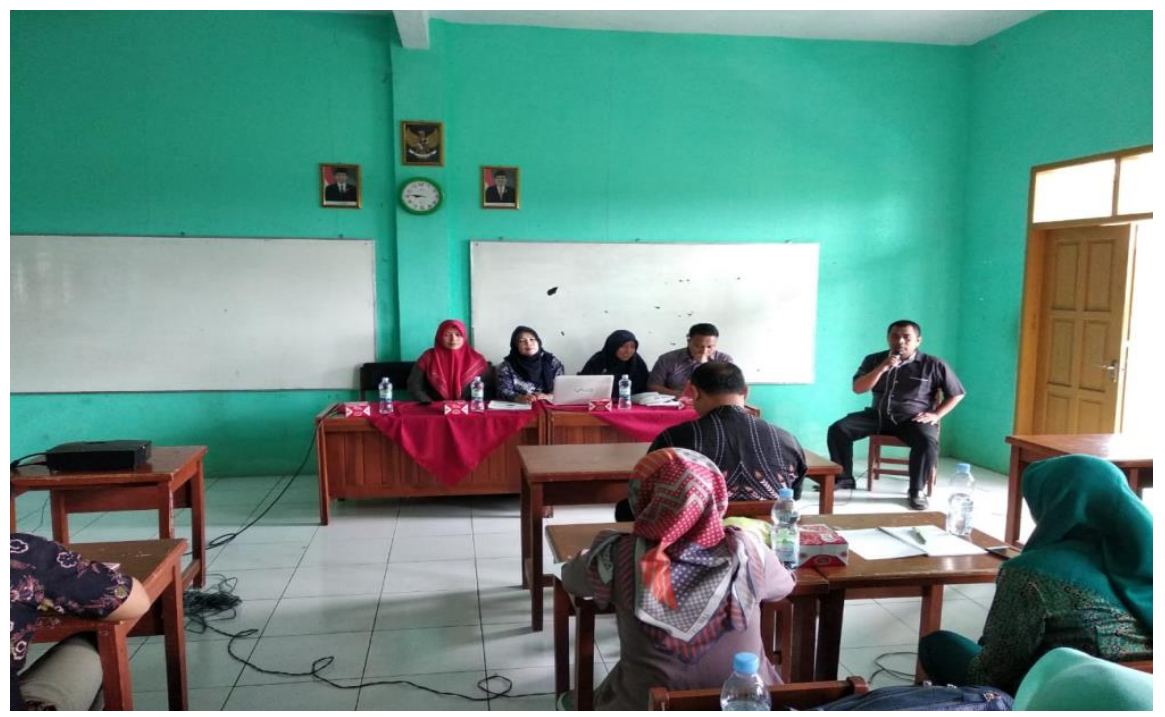

Gambar 1. Pembukaan Kegiatan Workshop 
Berdasarkan survey ke SMK AS-Shofa, tim bersama mitra memperoleh kesepakatan bahwa pelaksanaan IbBM yang berjudul "Workshop Pengembangan Media Pembelajaran Berbasis ICT" dilaksanakan pada bulan Juli 2019 bertempat di SMK AsShofa Kabupaten Tasikmalaya.

Kegiatan pengabdian ini dibuka oleh Wakasek Kurikulum di SMK AS-Shofa. Setelah pembukaan, dilanjutkan dengan pengenalan dan pemaparan materi workshop yang pertama yaitu alat peraga yang berbasis IT dan relevan dengan kurikulum 2013 yang sedang dilaksanakan pada saat ini.

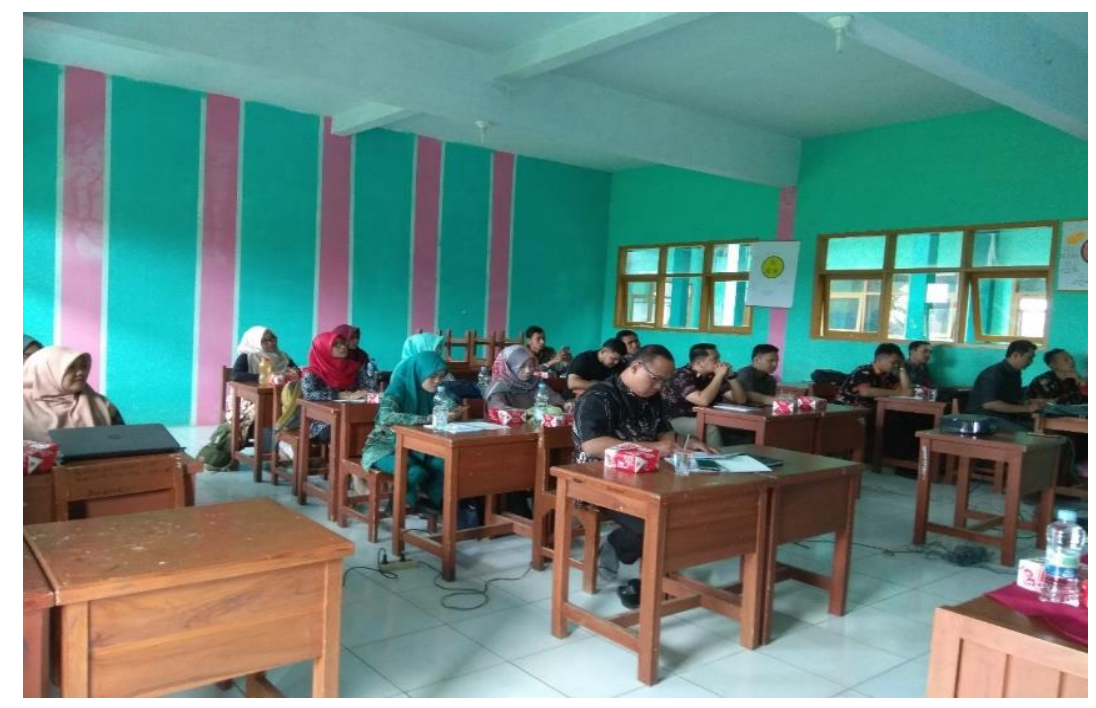

Gambar 2. Pemaparan Materi

Setelah pemaparan materi pertama dilanjutkan dengan pengenalan dan aplikasi pembuatan media pembelajaran berbasis ICT.

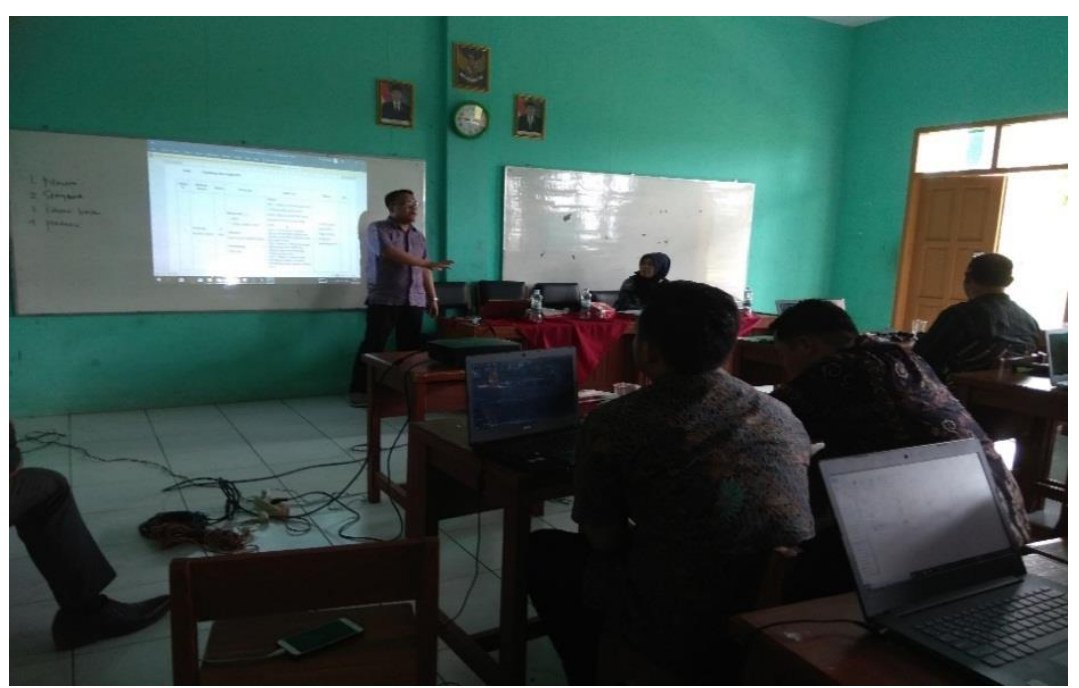

Gambar 3. Pengenalan dan Aplikasi Media Pembelajaran

Kegiatan pengabdian ini diikuti oleh 20 orang peserta yang mewakili setiap guru mata pelajaran di SMK AS-Shofa. 


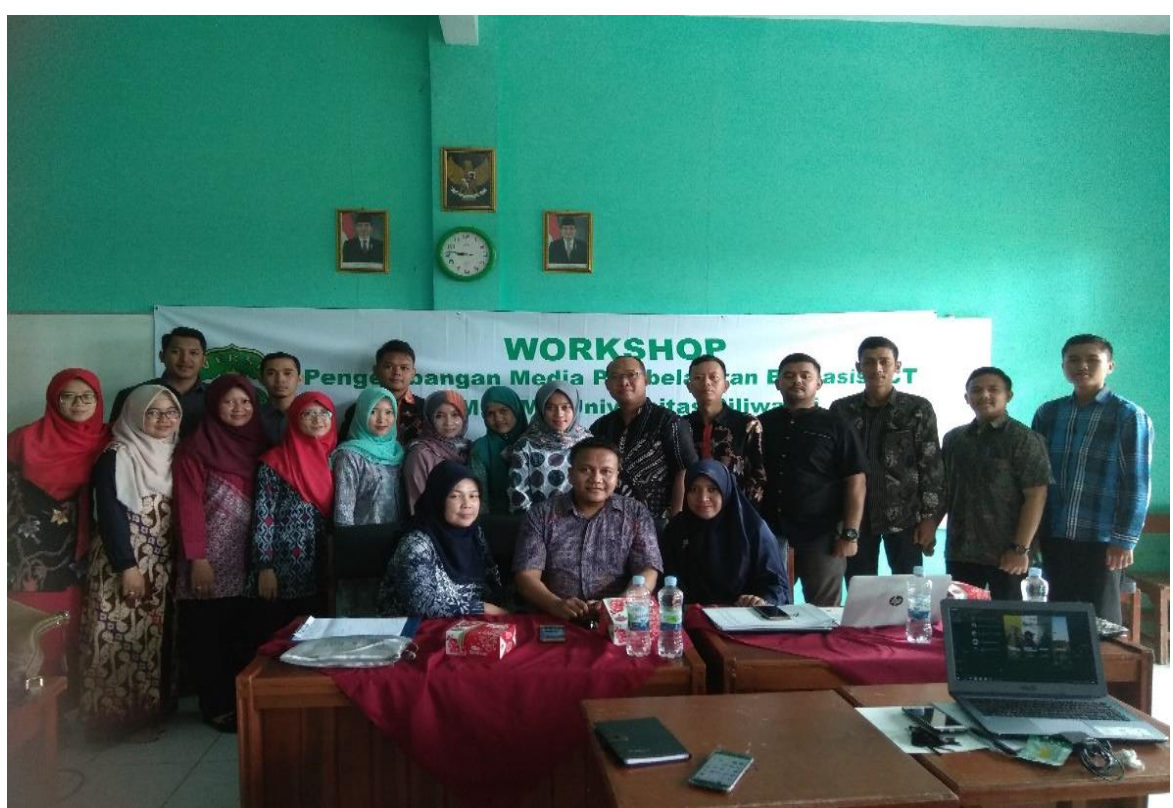

Gambar 4. Peserta Workshop Pengembangan Media Pembelajaran Berbasis ICT.

Dari awal pertemuan sampai akhir guru-guru terlihat sangat antusias mengikuti setiap kegiatan dalam workshop tersebut. Pada saat workshop guru-guru dikenalkan dan dilatih mengembangkan media pembelajaran berbassis ICT, sehingga guru-guru tidak kesulitan dalam menyampaikan materi pembelajaran dan hal ini akan berdampak pada meningkatnya pemahaman dan semangat belajar siswa.

Secara keseluruhan kegiatan pengadian pada masysarakat ini mampu memberikan dampak yang signifikan, terutama bagi guru-guru di SMK As-Shofa dalam mengaplikasikan dan mengembangkan media pembelajaran berbasis ICT.

\section{Kesimpulan}

Dari kegiatan yang sudah dilaksanakan oleh Tim Pengabdian Pada Masyarakat skim IbBM dengan judul "Workshop Pengembangan Media Pembelajaran Berbasis ICT" yang dilaksanakan melalui kegiatan tutorial dan workshop, diperoleh simpulan:

1. Meningkatnya wawasan dan kesadaran guru-guru di SMK As-Shofa tentang pentingnya penggunaan ICT dalam pembelajaran terutama dalam mengimplementasikan Kurtilas;

2. Meningkatnya keterampilan guru-guru di SMK as-Shofa dalam menggunakan ICT dalam media pembelajaran;

3. Guru mampu membuat media pembelajaran berbasis ICT dan menggunakannya dalam pembelajaran.

\section{Daftar Pustaka}

Muhson, A. (2010). Pengembangan media pembelajaran berbasis teknologi informasi. Jurnal Pendidikan Akuntansi Indonesia, 8(2).

Sahid. (2016). Pengembangan Media pembelajaran Berbasis ICT. Fakultas Matematika dan IImu Pengetahuan Alam UNY, Yogyakarta 
Santyasa, I. W. (2007). Landasan konseptual media pembelajaran. Universitas Pendidikan Ganesha

Yamasari, Y. (2010). Pengembangan media pembelajaran matematika berbasis ICT yang berkualitas. In Seminar Nasional Pascasarjana X-ITS. FMIPA Unesa.

Zainiyati, H.S. (2017). Pengembangan Media Pembelajaran Berbasis ICT, Kencana, Jakarta. 